\title{
Polignac's Conjecture with New Prime Number Theorem
}

\section{YinYue Sha*}

Dongling Engineering Center, Ningbo Institute of Technology, Zhejiang University, China

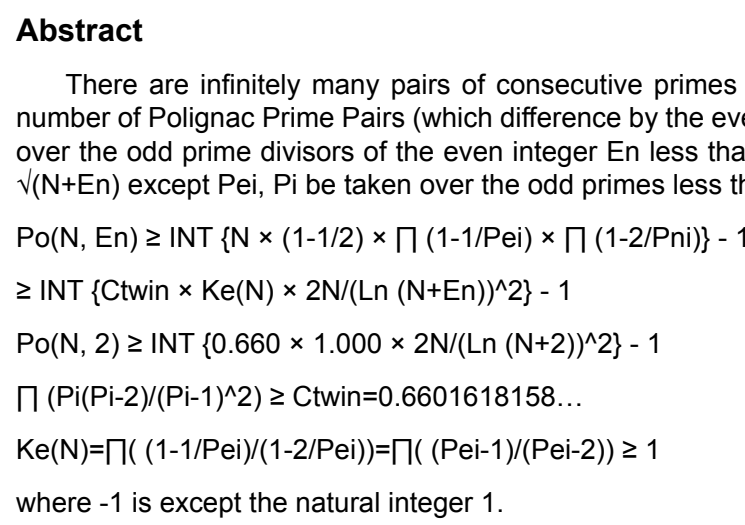

Keywords: Twin prime, Polignac prime, Bilateral sieve method

\section{Introduction}

In number theory, Polignac's conjecture was made by Alphonse de Polignac in 1849 and states: For any positive even number En, there are infinitely many prime gaps of size En. In other words: There are infinitely many cases of two consecutive prime numbers with difference En [1]

The conjecture has not yet been proven or disproven for a given value of En. In 2013 an important breakthrough was made by Zhang Yitang who proved that there are infinitely many prime gaps of size En for some value of $\mathrm{En}<70,000,000$ [2].

For $\mathrm{En}=6$, it says there are infinitely many primes $(\mathrm{p}, \mathrm{p}+6)$. For $\mathrm{En}=4$, it says there are infinitely many cousin primes $(\mathrm{p}, \mathrm{p}+4)$. For $E n=2$, it is the twin prime conjecture that there are infinitely many twin primes $(p, p+2)$ as shown in Figure 1. For $E n=0$, it is the new prime theorem

\section{The Polignac Prime of Even Integer}

For an any even integer En there exists a prime $\mathrm{P}$ for which the Polignac number $\mathrm{Q}=\mathrm{En}+\mathrm{P}$ is also prime. The Polignac Prime pairs shall be denoted by the representation $\mathrm{En}=\mathrm{Q}-\mathrm{P}=(\mathrm{En}+\mathrm{P})-\mathrm{P}$, where $\mathrm{P}$ and $\mathrm{Q}$ are primes and prime $\mathrm{P}\{\mathrm{P} \leq \mathrm{Q}\}$ is a Polignac prime of even integer En. Looking at the Polignac partition a different way, we can look at the number of distinct representations (or Polignac primes)that exist for En.

For example, as noted at the beginning of this discussion:

$$
\begin{aligned}
& 2=05-03=(2+03)-03 ; 2=07-05=(2+05)-05 ; \\
& 2=13-11=(2+11)-11 ; 2=19-17=(2+17)-17 ; \\
& 2=31-29=(2+29)-29 ; 2=43-41=(2+41)-41 ; \\
& 2=61-59=(2+59)-59 ; 2=73-71=(2+71)-71 ;
\end{aligned}
$$

where $3,5,11,17,29,41,59$ and 71 are Polignac primes of even integer 2 .

$$
\begin{aligned}
& 4=07-03=(4+03)-03 ; 4=11-07=(4+07)-07 ; \\
& 4=17-13=(4+13)-13 ; 4=23-19=(4+19)-19 ;
\end{aligned}
$$

$$
\begin{aligned}
& 4=41-37=(4+37)-37 ; 4=47-43=(4+43)-43 ; \\
& 4=71-67=(4+67)-67 ; 4=83-79=(4+79)-79 ;
\end{aligned}
$$

where $3,7,13,19,37,43,67$ and 79 are Polignac primes of even integer 4 .

$$
\begin{aligned}
& 6=11-05=(6+05)-05 ; 6=13-07=(6+07)-07 ; \\
& 6=17-11=(6+11)-11 ; 6=19-13=(6+13)-13 ; \\
& 6=23-17=(6+17)-17 ; 6=29-23=(6+23)-23 ; \\
& 6=37-31=(6+31)-31 ; 6=43-37=(6+37)-37 ; \\
& 6=47-41=(6+41)-41 ; 6=53-47=(6+47)-47 ; \\
& 6=59-53=(6+53)-53 ; 6=67-61=(6+61)-61 ; \\
& 6=73-67=(6+67)-67 ; 6=79-73=(6+73)-73 ; \\
& 6=89-83=(6+83)-83 ; 6=103-97=(6+97)-97 ;
\end{aligned}
$$

where $5,7,11,13,17,23,31,37,41,47,53,61,67,73,83$ and 97 are Polignac primes of even integer 6 .

It shows that generally the number of distinct representations (or Polignac primes) increases with increasing $\mathrm{N}$.

\section{The Sieve Method about the Polignac Primes}

Let $\mathrm{En}$ is an any even integer, $\mathrm{Ci}$ is a positive integer more not large than $\mathrm{N}$, then exists the formula as follows:

${ }^{*}$ Corresponding author: YinYue Sha, Dongling Engineering Center, Ningbo Institute of Technology, Zhejiang University, China, Tel: 5718517 2244; E-mail: shayinyue@qq.com

Received July 04, 2016; Accepted November 08, 2016; Published November 11, 2016

Citation: Sha YY (2016) Polignac's Conjecture with New Prime Number Theorem J Phys Math 7: 201. doi: 10.4172/2090-0902.1000201

Copyright: (c) 2016 Sha YY. This is an open-access article distributed under the terms of the Creative Commons Attribution License, which permits unrestricted use, distribution, and reproduction in any medium, provided the original author and source are credited. 


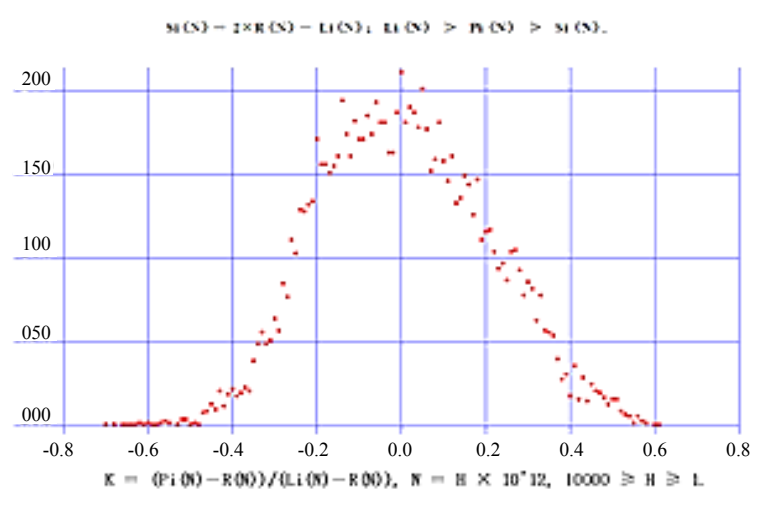

Figure 1: Riemann prime counting function with new prime number theorem.

\section{$\mathrm{En}=(\mathrm{En}+\mathrm{Ci})-\mathrm{Ci}$}

where $\mathrm{Ci}$ and $\mathrm{En}+\mathrm{Ci}$ are two positive integers more not large than $\mathrm{N}+\mathrm{En}$.

If $\mathrm{Ci}$ and $\mathrm{En}+\mathrm{Ci}$ any one can be divided by the prime anyone more

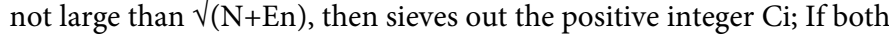
Po and En+Po can not be divided by all primes more not large than $\sqrt{ }(\mathrm{N}+\mathrm{En})$, then both the Po and En+Po are primes at the same time, where the prime Po is a Polignac prime of even integer En.

\section{The Total of Representations of Even Integer}

Let En is an any even integer, then exists the formula as follows:

$\mathrm{En}=(\mathrm{En}+\mathrm{Ci})-\mathrm{Ci}$

where $\mathrm{Ci}$ is the natural integer less than $\mathrm{N}$.

In terms of the above formula we can obtain the array as follows:

$(E n+1,1),(E n+2,2),(E n+3,3),(E n+4,4),(E n+5,5), \ldots,(E n+N, N)$.

From the above arrangement we can obtain the formula about the total of Polignac numbers of even integer En as follows:

$\mathrm{Ci}(\mathrm{N}, \mathrm{En})=\mathrm{N}=$ Total of integers $\mathrm{Ci}$ more not large than $\mathrm{N}$

\section{The Bilateral Sieve Method of Even Prime 2}

It is known that the number 2 is an even prime, and above arrangement from $(E n+1,1)$ to $(E n+N, N)$ can be arranged to the form as follows:

\section{$(E n+1,1),(E n+3,3),(E n+5,5), \ldots,(E n+N-X: X<2, N-X: X<2)$.}

$(E n+2,2),(E n+4,4),(E n+6,6), \ldots,(E n+N-X: X<2, N-X: X<2)$,

From the above arrangenment we can known that: Because the even integer En can be divided by the even prime 2, therefore, both $\mathrm{Ci}$ and $\mathrm{En}+\mathrm{Ci}$ can be or can not be divided by the even prime 2 at the same time.

The number of integers $\mathrm{Ci}$ that $\mathrm{Ci}$ and $\mathrm{En}+\mathrm{Ci}$ anyone can be divided by the even prime 2 is INT $(\mathrm{N} \times(1 / 2))$.

The number of integers $\mathrm{Ci}$ that both $\mathrm{Ci}$ and $\mathrm{En}+\mathrm{Ci}$ can not be divided by the even prime 2 is N-INT $(\mathrm{N} \times(1 / 2))=\mathrm{INT}\{\mathrm{N}-\mathrm{N} \times$ $(1 / 2)\}=\operatorname{INT}\{\mathrm{N} \times(1-1 / 2)\}$.

The density of integers $\mathrm{Ci}$ that both $\mathrm{Ci}$ and $\mathrm{En}+\mathrm{Ci}$ can not be divided by the even prime 2 (or the ratio of the number of integers $\mathrm{Ci}$ that both $\mathrm{Ci}$ and $\mathrm{En}+\mathrm{Ci}$ can not be divided by the even prime 2 to the total of integers Ci more not large than $\mathrm{N}$ ) as follows:

$$
\begin{aligned}
& \mathrm{Si}(\mathrm{N}, \text { En }, 2)=\operatorname{INT}(\mathrm{N} \times(1 / 2)), \mathrm{Ci}(\mathrm{N}, \mathrm{En}, 2)=\mathrm{N}-\mathrm{Si}(\mathrm{N}, \mathrm{En}, 2) \\
& \operatorname{Di}(\mathrm{N}, \mathrm{En}, 2)=\mathrm{Ci}(\mathrm{N}, \mathrm{En}, 2) /(\mathrm{N})=\mathrm{INT}\{\mathrm{N} \times(1-1 / 2)\} / \mathrm{N}
\end{aligned}
$$

\section{The Bilateral Sieve Method of Odd Prime 3}

It is known that the number 3 is an odd prime, and above arrangement from $(\mathrm{En}+1,1)$ to $(\mathrm{En}+\mathrm{N}, \mathrm{N})$ can be arranged to the form as follows:

$(E n+1,1),(E n+4,4),(E n+7,7), \ldots,(E n+N-X: X<3, N-X: X<3)$,
$(E n+2,2),(E n+5,5),(E n+8,8), \ldots,(E n+N-X: X<3, N-X: X<3)$,
$(E n+3,3),(E n+6,6),(E n+9,9), \ldots,(E n+N-X: X<3, N-X: X<3)$.

From the above arrangenment we can known that:

If the even integer En can be divided by odd prime 3, then both the $\mathrm{Ci}$ and $\mathrm{En}+\mathrm{Ci}$ can be or can not be divided by odd prime 3 at the same time.

The number of integers $\mathrm{Ci}$ that the $\mathrm{Ci}$ and $\mathrm{En}+\mathrm{Ci}$ anyone can be divided by odd prime 3 is INT $(\mathrm{N} \times(1 / 3))$.

The number of integers $\mathrm{Ci}$ that both $\mathrm{Ci}$ and $\mathrm{En}+\mathrm{Ci}$ can not be divided by odd prime 3 is $\mathrm{N}-\mathrm{INT}(\mathrm{N} \times(1 / 3))=\mathrm{INT}\{\mathrm{N}-\mathrm{N} \times(1 / 3)\}=\mathrm{INT}\{\mathrm{N} \times(1-$ $1 / 3)\}$.

The density of integers $\mathrm{Ci}$ that both $\mathrm{Ci}$ and $\mathrm{En}+\mathrm{Ci}$ can not be divided by odd prime 3 (or the ratio of the number of integers $\mathrm{Ci}$ that both $\mathrm{Ci}$ and $\mathrm{En}+\mathrm{Ci}$ can not be divided by the odd prime 3 to the total of integers Ci more not large than $\mathrm{N}$ ) as follows:

$$
\begin{aligned}
& \operatorname{Sei}(\mathrm{N}, \text { En, 3) }=\operatorname{INT}(\mathrm{N} \times(1 / 3)), \operatorname{Cei}(\mathrm{N}, \text { En, 3 })=\mathrm{N}-\operatorname{Sei}(\mathrm{N}, \text { En, 3) } \\
& \operatorname{Dei}(\mathrm{N}, \text { En, 3) }=\operatorname{Cei}(\mathrm{N}, \text { En, 3) } /(\mathrm{N})=\operatorname{INT}\{\mathrm{N} \times(1-1 / 3)\} / \mathrm{N}
\end{aligned}
$$

If the even integer En can not be divided by the odd prime 3, then both $\mathrm{Ci}$ and $\mathrm{En}+\mathrm{Ci}$ can not be divided by the odd prime 3 at the same time, that is the $\mathrm{Ci}$ and $\mathrm{En}+\mathrm{Ci}$ only one can be divided or both the $\mathrm{Ci}$ and $\mathrm{E}+\mathrm{Ci}$ can not be divided by the odd prime 3 .

The number of integers $\mathrm{Ci}$ that the $\mathrm{Ci}$ and $\mathrm{En}+\mathrm{Ci}$ anyone can be divided by the odd prime 3 is INT(N $\times(2 / 3))$.

The number of integers $\mathrm{Ci}$ that both the $\mathrm{Ci}$ and $\mathrm{En}+\mathrm{Ci}$ can not be divided by the odd prime 3 is N-INT $(\mathrm{N} \times(2 / 3))=\mathrm{INT}\{\mathrm{N}-\mathrm{N} \times$ $(2 / 3)\}=\operatorname{INT}\{\mathrm{N} \times(1-2 / 3)\}$.

The density of integers $\mathrm{Ci}$ that both $\mathrm{Ci}$ and $\mathrm{En}+\mathrm{Ci}$ can not be divided by odd prime 3 (or the ratio of the number of integers $\mathrm{Ci}$ that both $\mathrm{Ci}$ and $\mathrm{En}+\mathrm{Ci}$ can not be divided by the odd prime 3 to the total of integers Ci more not large than $\mathrm{N}$ ) as follows:

$$
\begin{aligned}
& \operatorname{Sni}(\mathrm{N}, \text { En, } 3)=\operatorname{INT}(\mathrm{N} \times(2 / 3)), \operatorname{Cni}(\mathrm{N}, \mathrm{En}, 3)=\mathrm{N}-\operatorname{Sni}(\mathrm{N}, \mathrm{En}, 3) \\
& \operatorname{Dni}(\mathrm{N}, \text { En }, 3)=\operatorname{Cni}(\mathrm{N}, \mathrm{En}, 3) /(\mathrm{N})=\operatorname{INT}\{\mathrm{N} \times(1-2 / 3)\} / \mathrm{N}
\end{aligned}
$$

\section{The Bilateral Sieve Method of Odd Prime 5}

It is known that the number 5 is an odd prime, and above arrangement from $(\mathrm{En}+1,1)$ to $(\mathrm{En}+\mathrm{N}, \mathrm{N})$ can be arranged to the form as follows:

$(E n+1,1),(E n+06,06),(E n+11,11), \ldots,(E n+N-X: X<5, N-X: X<5)$,

$(E n+2,2),(E n+07,07),(E n+12,12), \ldots,(E n+N-X: X<5, N-X: X<5)$

$(E n+3,3),(E n+08,08),(E n+13,13), \ldots,(E n+N-X: X<5, N-X: X<5)$, 
$(E n+4,4),(E n+09,09),(E n+14,14), \ldots,(E n+N-X: X<5, N-X: X<5)$,

$(E n+5,5),(E n+10,10),(E n+15,15), \ldots,(E n+N-X: X<5, N-X: X<5)$.

From the above arrangenment we can known that:

If the even integer En can be divided by odd prime 5, then both the $\mathrm{Ci}$ and $\mathrm{En}+\mathrm{Ci}$ can be or can not be divided by odd prime 5 at the same time.

The number of integers $\mathrm{Ci}$ that the $\mathrm{Ci}$ and $\mathrm{En}+\mathrm{Ci}$ anyone can be divided by odd prime 5 is INT $(\mathrm{N} \times(1 / 5))$.

The number of integers $\mathrm{Ci}$ that both $\mathrm{Ci}$ and $\mathrm{En}+\mathrm{Ci}$ can not be divided by odd prime 5 is $\mathrm{N}-\mathrm{INT}(\mathrm{N} \times(1 / 5))=\mathrm{INT}\{\mathrm{N}-\mathrm{N} \times(1 / 5)\}=\mathrm{INT}\{\mathrm{N} \times(1-$ $1 / 5)\}$.

The density of integers $\mathrm{Ci}$ that both $\mathrm{Ci}$ and $\mathrm{En}+\mathrm{Ci}$ can not be divided by odd prime 5 (the ratio of the number of integers $\mathrm{Ci}$ that both $\mathrm{Ci}$ and $\mathrm{En}+\mathrm{Ci}$ can not be divided by odd prime 5 to the total of integers Ci more not large than $\mathrm{N}$ ) as follows:

$$
\begin{aligned}
& \operatorname{Sei}(\mathrm{N}, \text { En, 5) }=\operatorname{INT}(\mathrm{N} \times(1 / 5)), \operatorname{Cei}(\mathrm{N}, \mathrm{En}, 5)=\mathrm{N}-\operatorname{Sei}(\mathrm{N}, \text { En, } 5) \\
& \operatorname{Dei}(\mathrm{N}, \text { En, 5) }=\operatorname{Cei}(\mathrm{N}, \text { En }, 5) /(\mathrm{N})=\mathrm{INT}\{\mathrm{N} \times(1-1 / 5)\} / \mathrm{N}
\end{aligned}
$$

If the even integer En can not be divided by the odd prime 5, then both $\mathrm{Ci}$ and $\mathrm{En}+\mathrm{Ci}$ can not be divided by the odd prime 5 at the same time, that is the $\mathrm{Ci}$ and $\mathrm{En}+\mathrm{Ci}$ only one can be divided or both the $\mathrm{Ci}$ and $\mathrm{En}+\mathrm{Ci}$ can not be divided by the odd prime 5 .

The number of integers $\mathrm{Ci}$ that the $\mathrm{Ci}$ and $\mathrm{En}+\mathrm{Ci}$ anyone can be divided by the odd prime 5 is INT $(\mathrm{N} \times(2 / 5))$.

The number of integers $\mathrm{Ci}$ that both the $\mathrm{Ci}$ and $\mathrm{En}+\mathrm{Ci}$ can not be divided by the odd prime 5 is N-INT $(\mathrm{N} \times(2 / 5))=\mathrm{INT}\{\mathrm{N}-\mathrm{N} \times$ $(2 / 5)\}=\operatorname{INT}\{\mathrm{N} \times(1-2 / 5)\}$.

The density of integers $\mathrm{Ci}$ that both $\mathrm{Ci}$ and $\mathrm{En}+\mathrm{Ci}$ can not be divided by odd prime 5 (or the ratio of the number of integers $\mathrm{Ci}$ that both $\mathrm{Ci}$ and $\mathrm{En}+\mathrm{Ci}$ can not be divided by the odd prime 5 to the total of integers Ci more not large than $\mathrm{N}$ ) as follows:

$$
\begin{aligned}
& \operatorname{Sni}(\mathrm{N}, \text { En }, 5)=\operatorname{INT}(\mathrm{N} \times(2 / 5)), \operatorname{Cni}(\mathrm{N}, \text { En }, 5)=\mathrm{N}-\mathrm{Sni}(\mathrm{N}, \text { En }, 5) \\
& \operatorname{Dni}(\mathrm{N}, \text { En }, 5)=\operatorname{Cni}(\mathrm{N}, \text { En }, 5) /(\mathrm{N})=\operatorname{INT}\{\mathrm{N} \times(1-2 / 5)\} / \mathrm{N}
\end{aligned}
$$

\section{The Sieve Function of Bilateral Sieve Method}

Let En is an even integer, then exists the formula as follows:

$\mathrm{En}=(\mathrm{En}+\mathrm{Ci})-\mathrm{Ci}$

where $\mathrm{Ci}$ is the natural integer less than $\mathrm{N}$.

In terms of the above formula we can obtain the array as follows:

$(E n+1,1),(E n+2,2),(E n+3,3),(E n+4,4),(E n+5,5), \ldots,(E n+N, N)$.

Let $\mathrm{Pi}$ be an odd prime less than $\sqrt{ }(\mathrm{N}+\mathrm{En})$, then the above arrangement can be arranged to the form as follows:

$$
\begin{aligned}
& (E n+1,1),(E n+P i+1, P i+1), \ldots,(E n+N-X: X<P i, N-X: X<P i), \\
& (E n+2,2),(E n+P i+2, P i+2), \ldots,(E n+N-X: X<P i, N-X: X<P i), \\
& (E n+3,3),(E n+P i+3, P i+3), \ldots,(E n+N-X: X<P i, N-X: X<P i), \\
& (E n+P i, P i),(E n+2 P i, 2 P i), \ldots,(E n+N-X: X<P i, N-X: X<P i) .
\end{aligned}
$$

If the even integer En can be divided by the odd prime Pei, then both the $\mathrm{Ci}$ and $\mathrm{En}+\mathrm{Ci}$ can be or can not be divided by the odd prime Pei at the same time.
The number of integers $\mathrm{Ci}$ that the $\mathrm{Ci}$ and $\mathrm{En}+\mathrm{Ci}$ anyone can be divided by the odd prime Pei is INT $(\mathrm{N} \times(1 / \mathrm{Pei}))$.

The number of integers $\mathrm{Ci}$ that both the $\mathrm{Ci}$ and $\mathrm{En}+\mathrm{Ci}$ can not be divided by the odd prime Pei is N-INT $(\mathrm{N} \times(1 / \mathrm{Pei}))=\mathrm{INT}\{\mathrm{N}-\mathrm{N} \times(1 /$ $\mathrm{Pei})\}=\operatorname{INT}\{\mathrm{N} \times(1-1 / \mathrm{Pei})\}$

The density of integers $\mathrm{Ci}$ that both the $\mathrm{Ci}$ and $\mathrm{En}+\mathrm{Ci}$ can not be divided by the odd prime Pei (or the ratio of the number of integers $\mathrm{Ci}$ that both the $\mathrm{Ci}$ and $\mathrm{En}+\mathrm{Ci}$ can not be divided by the odd prime Pei to the total of integers Ci more not large than $\mathrm{N}$ ) as follows: Pei)

Sei $(N$, En, Pei $)=I N T(N \times(1 / P e i)), \operatorname{Cei}(N$, En, Pei $)=N-S e i(N$, En,

$\operatorname{Dei}(\mathrm{N}$, En, Pei $)=\operatorname{Cei}(\mathrm{N}$, En, Pei $) /(\mathrm{N})=\operatorname{INT}\{\mathrm{N} \times(1-1 / \mathrm{Pei})\} / \mathrm{N}$

If the even integer En can not be divided by the odd prime Pni, then both the $\mathrm{Ci}$ and $\mathrm{En}+\mathrm{Ci}$ can not be divided by the odd prime Pni at the same time, that is the $\mathrm{Ci}$ and $\mathrm{En}+\mathrm{Ci}$ only one can be divided or both the $\mathrm{Ci}$ and En+Ci can not be divided by the odd prime Pni.

The number of integers $\mathrm{Ci}$ that the $\mathrm{Ci}$ and $\mathrm{En}+\mathrm{Ci}$ anyone can be divided by the odd prime Pni is INT(N $\times(2 / \mathrm{Pni}))$.

The number of integers $\mathrm{Ci}$ that both the $\mathrm{Ci}$ and $\mathrm{En}+\mathrm{Ci}$ can not be divided by the odd prime Pni is N-INT $(\mathrm{N} \times(2 / \mathrm{Pni}))=\mathrm{INT}\{\mathrm{N}-\mathrm{N} \times(2 /$ Pni) $\}=\operatorname{INT}\{\mathrm{N} \times(1-2 /$ Pni $)\}$.

The density of integers $\mathrm{Ci}$ that both the $\mathrm{Ci}$ and $\mathrm{En}+\mathrm{Ci}$ can not be divided by the odd prime Pni (or the ratio of the number of integers $\mathrm{Ci}$ that both the $\mathrm{Ci}$ and $\mathrm{En}+\mathrm{Ci}$ can not be divided by the odd prime Pni to the total of integers Ci more not large than $\mathrm{N}$ ) as follows: Pni)

$\operatorname{Sni}(\mathrm{N}$, En, Pni $)=\operatorname{INT}(\mathrm{N} \times(2 / \mathrm{Pni})), \mathrm{Cni}(\mathrm{N}, \mathrm{En}, \mathrm{Pni})=\mathrm{N}-\mathrm{Sni}(\mathrm{N}, \mathrm{En}$

$\operatorname{Dni}(\mathrm{N}, \mathrm{En}, \mathrm{Pni})=\mathrm{Cni}(\mathrm{N}, \mathrm{En}, \mathrm{Pni}) /(\mathrm{N})=\mathrm{INT}\{\mathrm{N} \times(1-2 / 5)\} / \mathrm{N}$

Let $\operatorname{Po}(\mathrm{N}$, En) be the number of Polignac Prime Pairs (which difference by the even integer En) less than an integer $(N+E n)$, Pei be taken over the odd prime divisors of the even integer En less than $\sqrt{ }(\mathrm{N}+\mathrm{En})$, Pni be taken over the odd primes less than $\sqrt{ }(\mathrm{N}+\mathrm{En})$ except Pei, Pi be taken over the odd primes less than $\sqrt{ }(\mathrm{N}+\mathrm{En})$, then exists the formulas as follows:

$\operatorname{Po}(\mathrm{N}, \mathrm{En}) \geq \operatorname{INT}\{\mathrm{N} \times \operatorname{Di}(\mathrm{N}, \mathrm{En}, 2) \times \Pi \operatorname{Dei}(\mathrm{N}, \mathrm{En}, \mathrm{Pei}) \times$ חDni(N,En,Pni) $\}-1$

$=\operatorname{INT}\{\mathrm{N} \times(1-1 / 2) \times \Pi(1-1 / \mathrm{Pei}) \times \Pi(1-2 / \mathrm{Pni})\}-1$

where -1 is except the natural integer 1 .

\section{The Polignac Prime Theorem}

From above we can obtain that:

Let $\operatorname{Po}(\mathrm{N}, \mathrm{En})$ be the number of Polignac Prime Pairs (which difference by the even integer En) less than an integer $(\mathrm{N}+\mathrm{En})$, Pei be taken over the odd prime divisors of the even integer En less than $\sqrt{ }(\mathrm{N}+\mathrm{En})$, Pni be taken over the odd primes less than $\sqrt{ }(\mathrm{N}+\mathrm{En})$ except Pei, Pi be taken over the odd primes less than $\sqrt{ }(\mathrm{N}+\mathrm{En})$, then exists the formulas as follows:

$\operatorname{Po}(\mathrm{N}, E n) \geq \operatorname{INT}\{\mathrm{N} \times \operatorname{Di}(\mathrm{N}, \mathrm{En}, 2) \times \Pi$ Dei(N,En,Pei $) \times$ ПDni(N,En,Pni) $\}-1$

$=\operatorname{INT}\{\mathrm{N} \times(1-1 / 2) \times \Pi(1-1 / \mathrm{Pei}) \times \Pi(1-2 / \mathrm{Pni})\}-1$

Apply the Prime Number Theorem as follows: 
Let $\mathrm{Pi}(\mathrm{N})$ be the number of primes less than or equal to $\mathrm{N}, \mathrm{Pi}$ $(3 \leq \mathrm{Pi} \leq \mathrm{Pm})$ be taken over the odd primes less than $\sqrt{ } \mathrm{N}$, then exists the formulas as follows:

$$
\begin{aligned}
& \operatorname{Pi}\left(\mathrm{N} \mid \mathrm{N} \geq 10^{\wedge} 4\right)=\mathrm{INT}\{\mathrm{N} \times(1-1 / 2) \times \Pi(1-1 / \mathrm{Pi})+\mathrm{m}+1\}-1 \\
& \geq \mathrm{INT}\{\mathrm{N} \times(1-1 / 2) \times \Pi(1-1 / \mathrm{Pi})\}-1 \geq \mathrm{INT}\{\mathrm{N} / \mathrm{Ln}(\mathrm{N})\}-1 \\
& \Pi\left(\mathrm{Pi}(\mathrm{Pi}-2) /(\mathrm{Pi}-1)^{\wedge} 2\right) \geq \mathrm{Ctwin}=0.6601618158 \ldots \\
& \mathrm{Ke}(\mathrm{N})=\Pi((1-1 / \mathrm{Pei}) /(1-2 / \mathrm{Pei}))=\Pi((\mathrm{Pei}-1) /(\mathrm{Pei}-2)) \geq 1
\end{aligned}
$$

From the above and the formula (20) we can obtain the formula as follows:

$\operatorname{Po}\left(\mathrm{N} \mid \mathrm{N} \geq 10^{\wedge} 4, \mathrm{En}\right) \geq \operatorname{INT}\{\mathrm{N} \times(1-1 / 2) \times \Pi(1-1 / \mathrm{Pei}) \times \Pi(1-2 /$ Pni) $\}-1$

$\geq \operatorname{INT}\left\{\mathrm{Ctwin} \times \mathrm{Ke}(\mathrm{N}) \times 2 \mathrm{~N} /(\operatorname{Ln}(\mathrm{N}+\mathrm{En}))^{\wedge} 2\right\}-1$

$\geq$ Ctwin $\times \operatorname{Ke}(\mathrm{N}) \times 2 \mathrm{~N} /(\operatorname{Ln}(\mathrm{N}+\mathrm{En}))^{\wedge} 2-2$

When the numbe $\mathrm{N} \rightarrow \infty$, we can obtain the formula as follows:

$$
\begin{aligned}
& \operatorname{Po}(\mathrm{N} \mid \mathrm{N} \rightarrow \infty, \mathrm{En}) \geq \mathrm{Ctwin} \times \mathrm{Ke}(\mathrm{N}) \times 2 \mathrm{~N} /(\operatorname{Ln}(\mathrm{N}+\mathrm{En}))^{\wedge} 2-2 \\
& \geq 0.660 \times 1.000 \times 2 \mathrm{~N} /(\operatorname{Ln}(\mathrm{N}+\mathrm{En}))^{\wedge} 2-2 \rightarrow \infty
\end{aligned}
$$

The above formula expresses that there are infinitely many pairs of Polignac primes which differ by every even number En.

When the En=2, then there are infinitely many twin primes.

\section{Every Even Integer Greater than Four Can be Expressed as a Sum of Two Odd Primes}

Every even integer greater than four can be expressed as a sum of two odd primes, and exists the formula as follows:

$\mathrm{Gp}(\mathrm{N}) \geq \operatorname{INT}\left\{\mathrm{Kpc} \times\right.$ Ctwin $\left.\times \mathrm{N} /(\operatorname{Ln} \mathrm{N})^{\wedge} 2\right\}-1 \geq \operatorname{INT}\{0.66016 \times \mathrm{N} /$ $\left.(\operatorname{Ln} \mathrm{N})^{\wedge} 2\right\}-1 \geq 185>>1$

where the $\mathrm{Gp}(\mathrm{N})$ be the number of primes $\mathrm{P}$ with N-P primes, or, equivalently, the $\mathrm{Gp}(\mathrm{N})$ be the number of ways of writing $\mathrm{N}$ as a sum of two primes, the $\mathrm{N}$ be the even integer greater than 30000 .

\section{The proof method of Goldbach's conjecture}

The Goldbach's Conjecture is one of the oldest unsolved problems in Number Theory. In its modern form, it states that every even integer greater than two can be expressed as a sum of two primes.

Let $\mathrm{N}$ be an even integer greater than 2 , and let $\mathrm{N}=(\mathrm{N}-\mathrm{Gp})+\mathrm{Gp}$, with $\mathrm{N}-\mathrm{Gp}$ and Gp prime numbers, the $\mathrm{Gp}\{\mathrm{Gp} \leq \mathrm{N} / 2\}$ be a Goldbach Prime of even integer N. Let $\mathrm{Gp}(\mathrm{N})$ be the number of Goldbach Primes of even integer $\mathrm{N}$. The number of ways of writing $\mathrm{N}$ as a sum of two prime numbers, when the order of the two primes is important, is thus $\mathrm{GP}(\mathrm{N})=2 \mathrm{Gp}(\mathrm{N})$ when $\mathrm{N} / 2$ is not a prime and is $\mathrm{GP}(\mathrm{N})=2 \mathrm{Gp}(\mathrm{N})-1$ when $N / 2$ is a prime. The Goldbach's Conjecture states that $G p(N)>0$, or, equivalently, that $\mathrm{GP}(\mathrm{N})>0$, for every even integer $\mathrm{N}$ greater than two.

We known that the Goldbach's Conjecture is true for every even integer $\mathrm{N}$ no greater than 30000 , therefore, we only need to prove that the Goldbach's Conjecture is true for every even integer $\mathrm{N}$ greater than 30000 , that is: $\mathrm{Gp}(\mathrm{N} \mid \mathrm{N}>30000) \geq 1$.

\section{TWO: The Sieve Method about the Goldbach Primes}

Let $\mathrm{N}$ be an even integer greater than 30000 , then the even integer $\mathrm{N}$ can be expressed to the form as follows:

$$
\mathrm{N}=(\mathrm{N}-\mathrm{Gn})+\mathrm{Gn}, \mathrm{Gn} \leq \mathrm{N} / 2
$$

where $\mathrm{Gn}$ be the positive integer no greater than N/2.

\section{Sieve method}

Let $\mathrm{N}-\mathrm{Gn}$ and $\mathrm{Gn}$ are two positive integers, if $\mathrm{N}-\mathrm{Gn}$ and $\mathrm{Gn}$ any one can be divisible by the prime $\mathrm{P}$, then sieves the positive integer $\mathrm{Gn}$; if both the N-Gp and Gp can not be divisible by the all primes no greater than $\sqrt{\mathrm{N}}$, then both the N-Gp and Gp are primes at the same time, the prime Gp be called the Goldbach Prime of even integer N.

Theorem 1: Let Pc be an odd prime factor of even integer $\mathrm{N}$ and no greater than $\sqrt{ } \mathrm{N}$, then the ratio of the number of integers Gp that both the N-Gp and Gp can not be divisible by the prime Pc to the total of integers $\mathrm{Gn}$ no greater than N/2 is follows: $(\mathrm{N} / 2)$

$\mathrm{R}(\mathrm{N}, \mathrm{Pc})=\mathrm{INT}\{\mathrm{N} / 2-\mathrm{N} / 2 / \mathrm{Pc}\} /(\mathrm{N} / 2)=\{\mathrm{INT}(\mathrm{N} / 2)-\mathrm{INT}(\mathrm{N} / 2 / \mathrm{Pc})\} /$

Proof: Because Pc is an odd prime factor of even integer N, therefore, both the N-Gn and Gn can or can not be divisible by prime $\mathrm{Pc}$ at the same time, then the number of integers $\mathrm{Gn}$ that the N-Gn and $\mathrm{Gn}$ any one can be divisible by the prime $\mathrm{Pc}$ is $\operatorname{INT}\{(\mathrm{N} / 2) / \mathrm{Pc}\}$, the number of integers $\mathrm{Gn}$ that both the $\mathrm{N}-\mathrm{Gn}$ and $\mathrm{Gn}$ can not be divisible by the prime $\mathrm{Pc}$ is $\{\mathrm{INT}(\mathrm{N} / 2)-\mathrm{INT}(\mathrm{N} / 2 / \mathrm{Pc})\}=\mathrm{INT}\{\mathrm{N} / 2-\mathrm{N} / 2 / \mathrm{Pc}\}$, the ratio of the number of integers $\mathrm{Gn}$ that both the $\mathrm{N}-\mathrm{Gn}$ and $\mathrm{Gn}$ can not be divisible by the prime Pc to the total of integers Gn no greater than $\mathrm{N} / 2$ is follows:

$\mathrm{R}(\mathrm{N}, \mathrm{Pc})=\{\mathrm{INT}(\mathrm{N} / 2)-\mathrm{INT}(\mathrm{N} / 2 / \mathrm{Pc})\} /(\mathrm{N} / 2)=\mathrm{INT}\{\mathrm{N} / 2-\mathrm{N} / 2 / \mathrm{Pc}\} /$

Theorem 2: Let Pn be an odd prime no factor of even integer $\mathrm{N}$ and no greater than $\sqrt{N}$, then the ratio of the number of integers $\mathrm{Gn}$ that both the N-Gn and Gn can not be divisible by the prime Pn to the total of integers $\mathrm{Gn}$ no greater than $\mathrm{N} / 2$ is follows:

$\mathrm{R}(\mathrm{N}, \mathrm{Pn})=\mathrm{INT}\{\mathrm{N} / 2-\mathrm{N} / \mathrm{Pn}\} /(\mathrm{N} / 2)=\{\mathrm{INT}(\mathrm{N} / 2)-\mathrm{INT}(\mathrm{N} / \mathrm{Pn})\} /(\mathrm{N} / 2)$

Proof: Because the Pn is an odd prime no factor of even integer N, therefore, both the N-Gn and Gn can not be divisible by the prime Pn at the same time, that is the N-Gn and Gn only one can be divisible or both the N-Gn and Gn can not be divisible by the prime Pn, then the number of integers $\mathrm{Gn}$ that the N-Gn and $\mathrm{Gn}$ any one can be divisible by the prime Pn is INT\{N/Pn\}, the number of integers Gn that both the N-Gn and Gn can not be divisible by the prime Pn is $\{\mathrm{INT}(\mathrm{N} / 2)$ $\mathrm{INT}(\mathrm{N} / \mathrm{Pn})\}=\mathrm{INT}\{\mathrm{N} / 2-\mathrm{N} / \mathrm{Pn}\}$, the ratio of the number of integers $\mathrm{Gn}$ that both the N-Gn and Gn can not be divisible by the prime Pn to the total of integers $\mathrm{Gn}$ no greater than N/2 is follows: $(\mathrm{N} / 2)$

$\mathrm{R}(\mathrm{N}, \mathrm{Pn})=\{\mathrm{INT}(\mathrm{N} / 2)-\operatorname{INT}(\mathrm{N} / \mathrm{Pn})\} /(\mathrm{N} / 2)=\mathrm{INT}\{\mathrm{N} / 2-\mathrm{N} / \mathrm{Pn}\} /$

Theorem 3: The integer 2 is an even prime factor of even integer $\mathrm{N}$, the ratio of the number of integers $\mathrm{Gn}$ that both the N-Gn and $\mathrm{Gn}$ can not be divisible by the even prime 2 to the total of integers $\mathrm{Gn}$ no greater than $\mathrm{N} / 2$ is follows:

\section{$\mathrm{R}(\mathrm{N}, 2)=\mathrm{INT}\{\mathrm{N} / 2-\mathrm{N} / 2 / 2\} /(\mathrm{N} / 2)=\{\mathrm{INT}(\mathrm{N} / 2)-\mathrm{INT}(\mathrm{N} / 2 / 2)\} /(\mathrm{N} / 2)$}

Proof: Because the 2 is an even prime factor of even integer $\mathrm{N}$, therefore, both the N-Gn and Gn can be divisible or can not be divisible by the even prime 2 at the same time, then the number of integers $\mathrm{Gn}$ that the N-Gn and $\mathrm{Gn}$ any one can be divisible by the even prime 2 is INT $\{\mathrm{N} / 2 / 2\}$, the number of integers Gn that both the $\mathrm{N}-\mathrm{Gn}$ and $\mathrm{Gn}$ can not be divisible by the even prime 2 is $\{\mathrm{INT}(\mathrm{N} / 2)$ - 
$\operatorname{INT}(\mathrm{N} / 2 / 2)\}=\operatorname{INT}\{\mathrm{N} / 2-\mathrm{N} / 2 / 2\}$, the ratio of the number of integers $\mathrm{Gn}$ that both the N-Gn and Gn can not be divisible by the even prime 2 to the total of integers $\mathrm{Gn}$ no greater than N/2 is follows:

$\mathrm{R}(\mathrm{N}, 2)=\{\mathrm{INT}(\mathrm{N} / 2)-\mathrm{INT}(\mathrm{N} / 2 / 2)\} /(\mathrm{N} / 2)=\mathrm{INT}\{\mathrm{N} / 2-\mathrm{N} / 2 / 2\} /(\mathrm{N} / 2)$

Three: The Number of Goldbach Primes of Even Integer

Let $\mathrm{Gp}(\mathrm{N})$ be the number of Goldbach primes of even integer $\mathrm{N}$, let $\mathrm{Gp}(\mathrm{N}, \mathrm{Pn})$ be the number of Goldbach primes no greater than $\sqrt{ } \mathrm{N}$, then exists the formulas as follows:

$\mathrm{Gp}(\mathrm{N})=\operatorname{INT}\{(\mathrm{N} / 2) \times \mathrm{R}(\mathrm{N}, 2) \times \Pi \mathrm{R}(\mathrm{N}, \mathrm{Pci}) \times \Pi \mathrm{R}(\mathrm{N}, \mathrm{Pni})\}+$ $\mathrm{Gp}(\mathrm{N}, \mathrm{Pni})-1$ (if N-1 prime)

$=\operatorname{INT}\{(\mathrm{N} / 2) \times(1-1 / 2) \times \Pi(1-1 / \mathrm{Pci}) \times \Pi(1-2 / \mathrm{Pni})\}+\mathrm{Gp}(\mathrm{N}, \mathrm{Pni})-1($ if $\mathrm{N}-1$ prime)

Where Pci and Pni are odd primes no greater than $\sqrt{ } \mathrm{N}$.

Let $\operatorname{Pi}(\mathrm{N})$ be the number of primes less than an integer $\mathrm{N}$, then, be the formula as follows:

$\operatorname{Pi}(\mathrm{N}) \equiv \operatorname{INT}\{\mathrm{N} \times(1-1 / \mathrm{P} 1) \times(1-1 / \mathrm{P} 2) \times \ldots \times(1-1 / \mathrm{Pm})+\mathrm{m}-1\} \equiv$ $\mathrm{P}(\mathrm{N})+\mathrm{Pi}(\sqrt{ } \mathrm{N})-1$

$\operatorname{Pi}(\mathrm{N}) \approx \operatorname{Psha}(\mathrm{N}) \equiv \operatorname{Li}(\mathrm{N})-1 / 2 \times \operatorname{Li}\left(\mathrm{N}^{\wedge} 0.5\right)$

$\mathrm{P}\left(\mathrm{N} \geq \mathrm{N} \geq 10^{\wedge} 9\right) \geq 2 /(1+\sqrt{ }(1-4 / \operatorname{Ln}(\mathrm{N}))) \times \mathrm{N} / \operatorname{Ln}(\mathrm{N}) \geq \mathrm{N} /(\operatorname{Ln}(\mathrm{N})-1)$

$\mathrm{P}\left(\mathrm{N} \geq \mathrm{N} \geq 10^{\wedge} 4\right) \equiv \operatorname{INT}\{\mathrm{N} \times(1-1 / 2) \times \Pi(1-1 / \mathrm{Pi})\} \geq \mathrm{N} / \mathrm{Ln}(\mathrm{N})$

\section{The Proof of Goldbach's Conjecture}

Theorem 4: Every even integer greater than 30000 can be expressed as a sum of two odd primes.

Proof: According to the formula (5),

We can obtain the formula as follows:

$\mathrm{Gp}(\mathrm{N})+1 \geq \operatorname{INT}\{(\mathrm{N} / 2) \times(1-1 / 2) \times \Pi(1-1 / \mathrm{Pci}) \times \Pi(1-2 / \mathrm{Pni})\}$

$$
\begin{aligned}
& =\operatorname{INT}\{(\mathrm{N} / 2) \times(1-1 / 2) \times \Pi((\mathrm{Pci}-1) /(\mathrm{Pci}-2)) \times \Pi(1-2 / \mathrm{Pci}) \times \Pi(1-2 / \mathrm{Pni})\} \\
& =\operatorname{INT}\{(\mathrm{N} / 2) \times(1-1 / 2) \times \Pi((\mathrm{Pci}-1) /(\mathrm{Pci}-2)) \times \Pi(1-2 / \mathrm{Pi})\} \\
& =\operatorname{INT}\{(\mathrm{N} / 2) \times(1-1 / 2) \times \mathrm{Kpc} \times \Pi(1-2 / \mathrm{Pi}) / \Pi(1-1 / \mathrm{Pi}) \wedge 2 \times \Pi(1-1 / \\
& \wedge 2\} \\
& =\operatorname{INT}\left\{(\mathrm{N} / 2) \times(1-1 / 2) \times \mathrm{Kpc} \times \Pi\left(1-1 /(\mathrm{Pi}-1)^{\wedge} 2\right) \times \Pi(1-1 / \mathrm{Pi}) \wedge 2\right\} \\
& \geq \operatorname{INT}\left\{(\mathrm{N} / 2) \times(1-1 / 2) \times \mathrm{Kpc} \times \mathrm{Ctwin} \times \Pi(1-1 / \mathrm{Pi})^{\wedge} 2\right\}
\end{aligned}
$$$$
\left.\mathrm{Pi})^{\wedge} 2\right\}
$$

Apply the formula (6), we can obtain the formula as follows:

$\mathrm{Gp}(\mathrm{N} \mid \mathrm{N} \geq 30000) \geq \operatorname{INT}\{(\mathrm{N} / 2) \times(1-1 / 2) \times \mathrm{Kpc} \times$ Ctwin $\times \Pi(1-1 /$ $\left.\mathrm{Pi})^{\wedge} 2\right\}-1$

$\geq \operatorname{INT}\left\{\operatorname{Kpc} \times\right.$ Ctwin $\left.\times \mathrm{N} / \operatorname{Ln}(\mathrm{N})^{\wedge} 2\right\}-1 \geq \operatorname{INT}\{0.66016 \times \mathrm{N} /$ $\operatorname{Ln}(\mathrm{N}) \wedge 2\}-1$

$$
\geq \operatorname{INT}\{0.66016 \times(30000) / \operatorname{Ln}(30000) \wedge 2\}-1=\operatorname{INT}\{186.355 \ldots\}-1=185
$$

From above formula (8) we can obtain that:

Every even integer greater than 30000 can be expressed as a sum of two odd primes.

\section{Conclusion}

For every even integer En there are infinitely many pairs of Polignac primes which difference by En.

When the En=0, we can obtain New Prime Number Theorem: Let $\operatorname{Pi}(\mathrm{N})$ be the number of primes less than or equal to $\mathrm{N}$, for any real number N, the New Prime Number Theorem can be expressed by the formula as follows: $\mathrm{Pi}(\mathrm{N})=\mathrm{R}(\mathrm{N})+\mathrm{K} \times(\mathrm{Li}(\mathrm{N})-\mathrm{R}(\mathrm{N})), 1>\mathrm{K}>-1$. The Goldbach's Conjecture is a Complete Correct Theorem.

\section{References}

1. Tattersall JJ (2005) Elementary number theory in nine chapters. Cambridge University Press, UK.

2. Erica K (2013) Unheralded Mathematician Bridges the Prime Gap. Simons Science News, China. 